\title{
THE RELATIONSHIP BETWEEN DESIGN AND CUTTING EFFICIENCY OF DENTAL BURS
}

\author{
E. E. HENRY, M.S.E., AND F. A. PEYTON, D.Sc.
}

Physical Research Laboratory, School of Dentistry, University of Michigan, Ann Arbor, Mich.

\section{INTRODUCTION}

$\mathbf{R}^{\text {ECENTLY several articles have been presented which have deseribed in }}$ some degree the heat generation, the vibration characteristics, and the cutting efficiency of various rotating dental instruments. ${ }^{1-6}$ These reports have indicated that the operating characteristics of rotating instruments are interrelated to some degree and are modified by the speed of operation and the force applied to the instrument. The previous reports have given little attention to the matter of instrument design as it is related to the eutting efficiency and functional life of the dental bur.

The cutting efficiency of a rotating dental instrument may be considered the ability of that instrument to remove a maximum amount of tooth tissue with a minimum of effort and time involved in the operation. Closely related to the cutting efficieney characteristic of the instrument is its functional life, which may be considered the time interval through which the instrument may be used effectively to cut tooth tissue. Both the efficiency and the functional life of the rotating instrument are no doubt interrelated, and both characteristics are of significance to the practitioner in his effort to shape the eavity with a minimum of time and effort.

It was the purpose of this study to determine some of the factors of design which influence the relative cutting efficiency and the functional life of the steel and carbide dental bur. Because of the manner in which the study was conducted, it has been to some degree a survey of the products available to the profession. This was not, however, the primary purpose of the investigation. It has been observed empirically by many clinical operators that there is a variation in the behavior of different products with respect to both the cutting efficiency characteristies and the relative life of the eutting instrument. It was the basic purpose of this study, therefore, to determine if there were some fundamental reasons of design which might account for this observed difference in operating behavior. Some of these differences are described in this report.

\section{METHOD OF STUDY}

For this study, thirteen different brands of No. 557 steel and carbide burs were obtained through the local retail trade outlet. A total of nine different brands of No. 37 steel and carbide burs were obtained from the same source.

\footnotetext{
This study was supported by a grant from the National Dental Research Institute, United States Public Health Service, Project D-47C.

Presented at the meeting of the Dental Materials Group, I.A.D.R., Philadelphia, March 20-22, 1953 (J. D. Res. 32: 709, 1953).

Received for publication, March 28, 1953.
} 
These burs were used because previous studies on heat generation have concentrated on these two designs for comparison. Throughout this report, only code numbers are used since it is not intended to condemn or justify one product over another in this early stage of the investigation. It is of greater concern to this study to consider some of the basic factors of design which are important to favorable operating characteristics of dental burs in general.

From the standpoint of design, it is reasonable to assume that the number of teeth or flutes on the bur, the angle at which these flutes are formed, and the amount of ehip clearance space ahead of the tooth are all significant to the operation of the bur. These are variables which are related to any basic design, such as the No. 557 or the No. 37 dental bur.

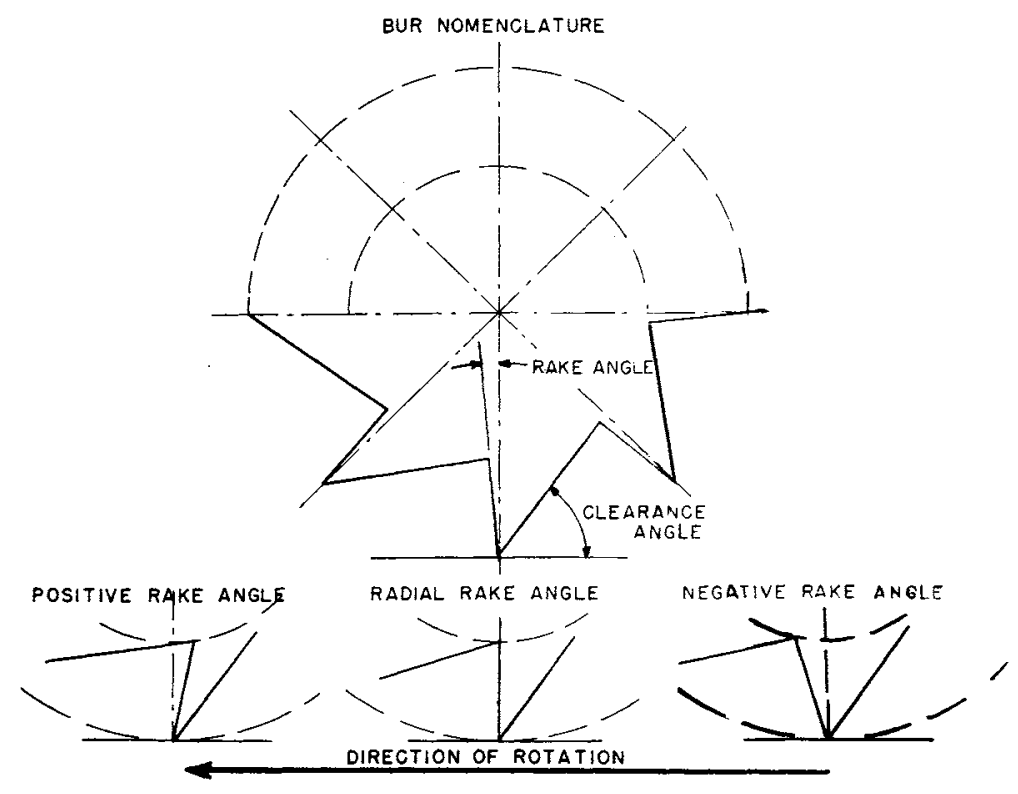

Fig. 1.-Cross-section schematic design of bur.

In Fig. 1 is shown a schematic cross-section design of a dental bur. This illustration indicates how an eight-fluted bur might be cut from round bur stock by shaping the teeth or flutes on the bur. The illustration indicates a clockwise rotation of the finished bur with various angles known as rake angles and chip clearance angles for the different teeth. When the rake angle is such that a line parallel to the face of the tooth will pass through the center of the bur, then the angle is described as a radical rake angle. As indicated in the bottom portion of the diagram, either positive or negative rake angles may be formed on the flute of the bur. The more positive the rake angle, the more effective is the cutting action of the tooth; while the more negative the rake angle, the less effective is the cutting action of the tooth. Another factor which can be observed from the central illustration in this figure is the size of the clearance angle, which is the angle on the trailing edge of the tooth. This angle may also 
vary from a very shallow angle to one that is quite deep. In bur design, there is probably a proper balance between the rake angle and clearance space which gives effectiveness and life to the instrument when operated at various speeds and pressures.

Fig. 2.
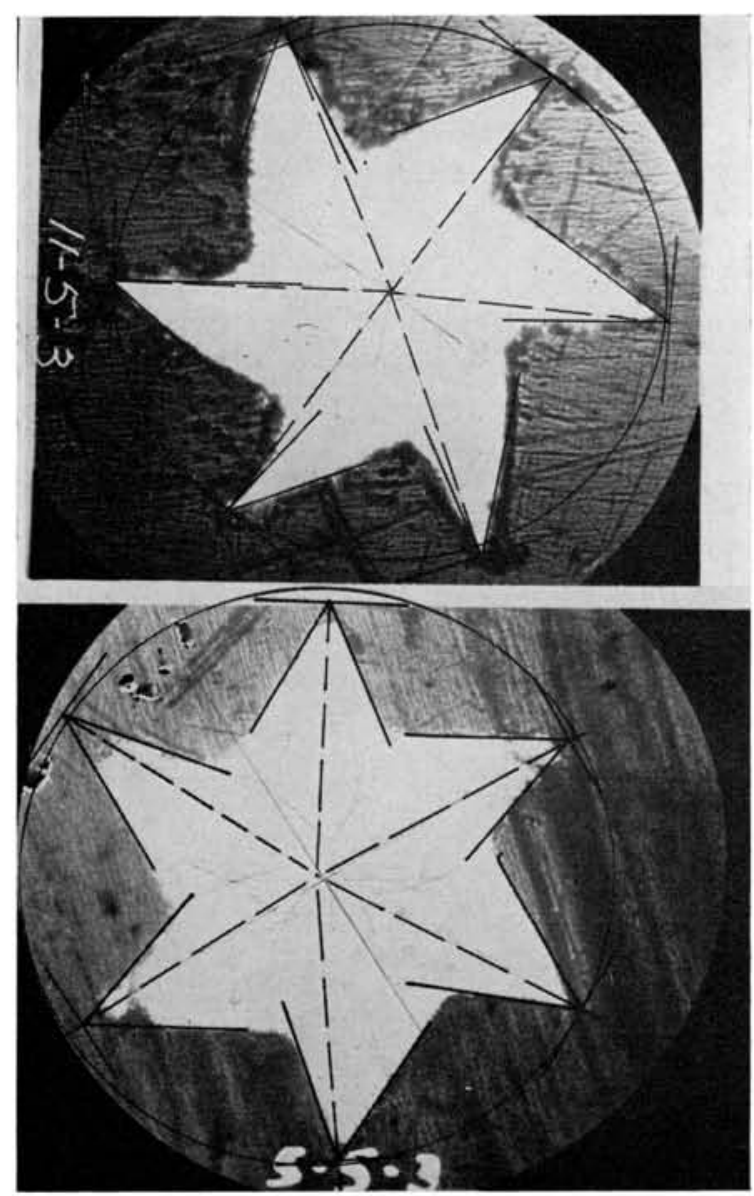

Fig. 3.

Fig. 2.-Six-tooth bur (No. 11-5-3).

Fig. 3.-Six-tooth bur (No. 5-5-3).

It has been observed that considerable variation exists among the various commercial products available with regard to both the rake angle and the chip clearance angle which are employed in the design of the burs. In order to examine the angle formed by the various teeth, four representative burs of each product were mounted in clear plastic so that the outermost $0.5 \mathrm{~mm}$. end of the bur could be polished away. With the burs thus mounted, it was possible to make a cross-section examination of the basic bur design for the various products being studied. 
In Fig. 2 is shown a six-tooth bur of a No. 557 design. This cross-section view shows the bur which is typical of this product to have a rake angle which approaches the radial line. Considerable chip clearance space exists in this bur, and in general it would seem well designed as an effective cutting bur. It may be questioned, however, whether or not a bur with this design will not have the tips of the teeth turned readily, or worn away, during the process of cutting hard tooth tissue.

Fig. 4.
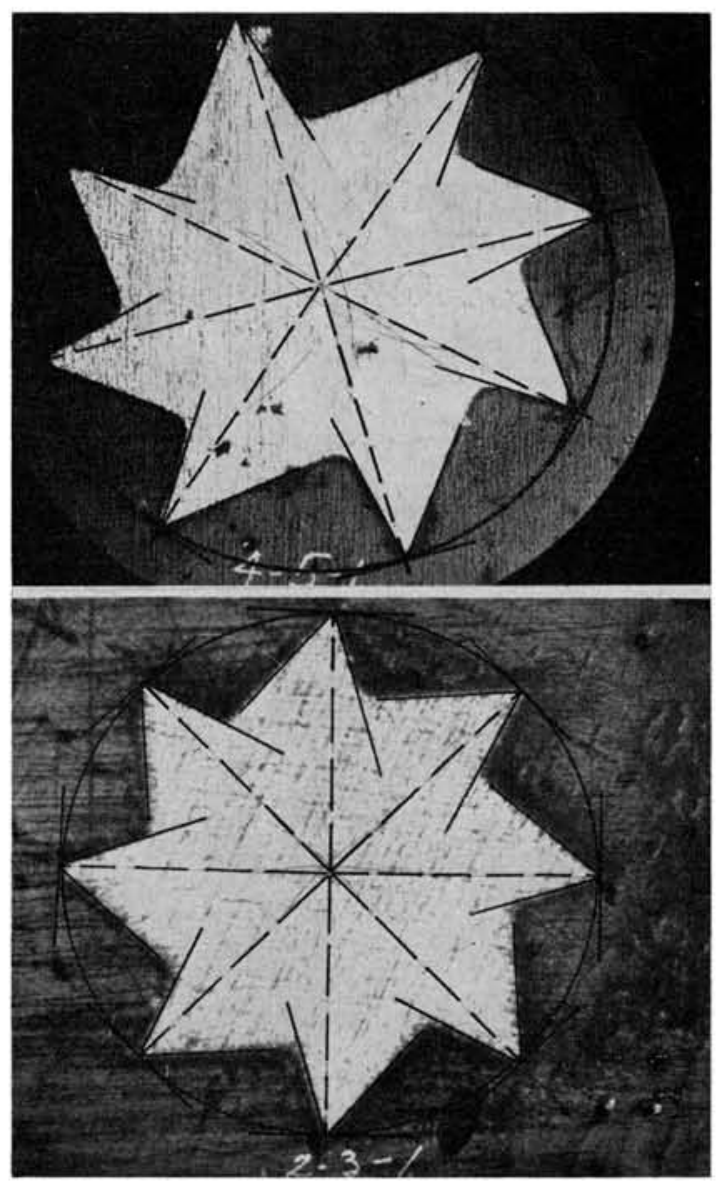

Fig. 5 .

Fig. 4,-Eight-tooth bur (No. 4-5-1).

Fig. 5.-Eight-tooth bur (No. 2-3-1).

The bur represented in Fig. 3 illustrates another typical example of a sixtooth bur which is entirely different in appearance from the cross-section view of the previous bur. This bur has a pronounced negative rake angle, even though it is a No. 557 bur of essentially the same design and intended purpose as the previous bur. It would seem that this bur would offer much less positive eutting action and perhaps is less efficient in its operation, even though it may 
have a longer life than the bur previously illustrated. It will be observed that this bur also has a large chip clearance angle.

It has been observed in examining various products available that sixtooth No. 557 burs often are spiral in design, whereas eight-tooth burs have relatively no spiral and often are entirely straight. An eight-tooth No. 557 bur is illustrated in Fig. 4. It can be seen that this bur has a less negative rake angle than did the six-tooth bur in Fig. 3. This variation in rake angle was observed to exist in both No. 557 and No. 37 type burs. The eight-tooth No. 37 bur, which is illustrated in Fig. 5, likewise shows an appreciable negative rake angle. The chip clearance angle in this bur also seems to be less than some illustrated in the previous figures. These cross-section views illustrate the variations which are typical of different burs that are available to the profession.

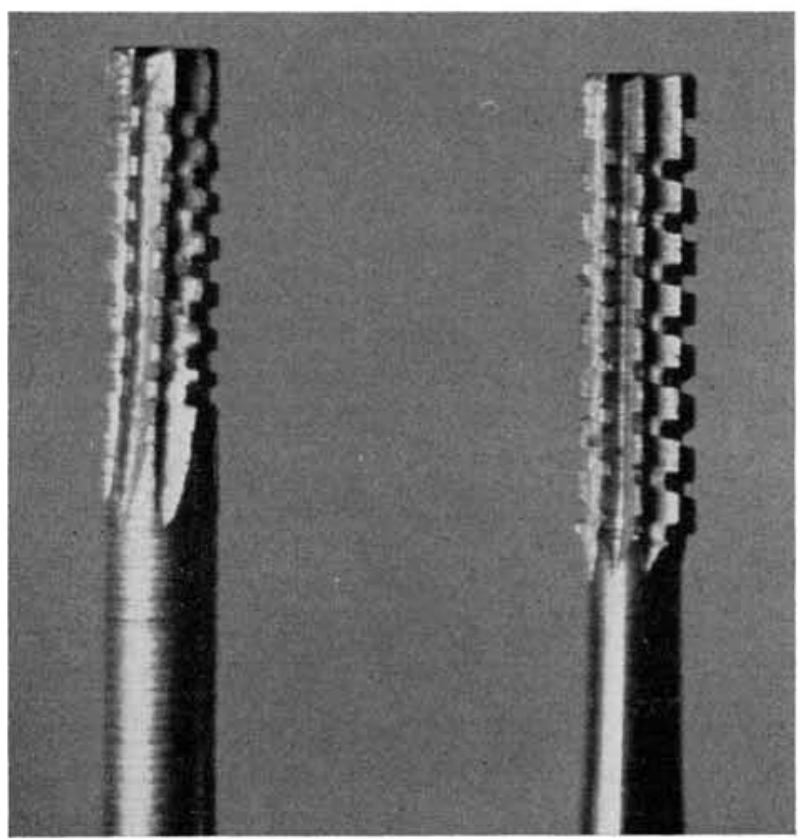

Fig. 6.- Straight fissure cross-cut burs.

Not only does the cross-section examination of various dental burs reveal that there is a difference between the various products available, but also an examination of the microscopic surface appearance of the burs varies greatly. Two eight-tooth straight No. 557 fissure cross-cut burs are illustrated in Fig. 6 . The microscopic examination of the bur on the left indicates that it is less well formed and that the teeth on the bur at the right are much cleaner than those on the bur at the left. There is also a lack of uniformity in length of the head of the bur. Both burs were picked at random from their respective products and are unused.

Such variation as has been observed in the No. 557 type of bur is also common in the No. 37 type of bur. Some of the variations that exist in the 
No. 37 type of bur are shown in Fig. 7. This represents three new burs which indicate variations in the cone angle, the length, and the diameter of the bur head. This represents considerable lack of standardization in products of the same basic design, and when combined with the eross-section variation in design indicated previously, it becomes evident that the operating characteristies of different products may vary greatly.

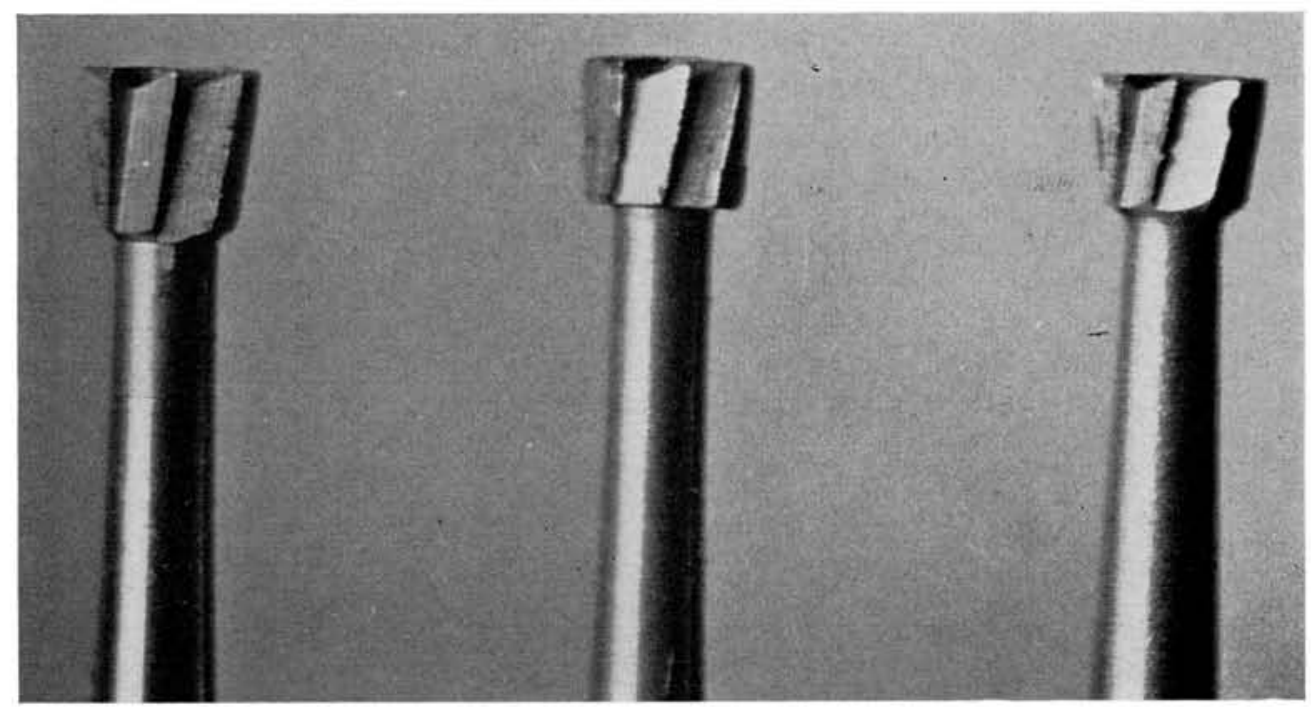

Fig. 7.-Variations in No. 37 burs.

TOOTH ANGLES AND CHIP SPACE

Measurements of both the No. 557 and the No. 37 burs have indicated that there is a measurable variation both in the rake angle and the clearance angle of different products. In Table I are shown some of the angle values which were observed for different products. The column at the left of Table I indicates the specimen number. The top ten samples represent No. 557 steel burs, and the bottom seven represent No. 37 steel burs. The mean rake angle values are given in the second column. It will be observed that all values are negative and that the mean value varies from minus 2 to minus 16 for the No. 557 burs, and from minus 4 to minus 28 for the No. 37 burs. The range for the No. 557 burs was from a positive 6 to a minus 21 degree value, and for the No. 37 burs it was a minus 2 to a minus 30 degree value. Some extreme values are observed; for example, the No. 5-5-3 in the No. 557 series has the greatest negative rake angle, and the No. 3-3-2 in the No. 37 series has the greatest negative rake angle. The clearance angle values are shown in the column at the right. The mean for the clearance angle value in the No. 557 series was observed to be slightly greater than the mean clearance angle for the No. 37 type of bur. There is a great variation in values observed within burs of various products, as well as between burs of the different products that were examined. 
TABLE I

ANgles of STEel Burs

\begin{tabular}{|c|c|c|c|c|}
\hline \multirow[b]{2}{*}{ SPECIMEN } & \multicolumn{2}{|c|}{ RAKE ANGLE VALUES } & \multicolumn{2}{|c|}{ CLEARANCE ANGLE VALUES } \\
\hline & MEAN & RANGE & MEAN & RANGE \\
\hline \multicolumn{5}{|l|}{ No. $557:$} \\
\hline $1-5-3$ & -13 & -8 to -20 & 52 & 49 to 56 \\
\hline $2-5 \cdot 2$ & -8.4 & -8 to -10 & 56 & 55 to 57 \\
\hline $3-5-3$ & -13 & -9 to -21 & 54 & 50 to 58 \\
\hline $4-5-1$ & -12.1 & -9 to -14 & 54 & 49 to 59 \\
\hline $5-5-3$ & -16 & -14 to -20 & 61 & 57 to 62 \\
\hline $6 \cdot 5 \cdot 1$ & -11.2 & -5 to -17 & 51 & 43 to 57 \\
\hline $9-5-3$ & -11.1 & -7 to -15 & 57 & 51 to 62 \\
\hline $11-5 \cdot 3$ & -2 & +6 to -5 & 55 & 50 to 60 \\
\hline $12-5-1$ & $-\overline{5}$ & +2 to -10 & 54 & 49 to 62 \\
\hline $13-5-3$ & -10.7 & -6 to -14 & 52 & 48 to 56 \\
\hline \multicolumn{5}{|l|}{ No. $37:$} \\
\hline $1-3-1$ & -9.5 & -6 tó -18 & 48 & 41 to 56 \\
\hline $2-3-1$ & -18 & -17 to -20 & 49 & 49 to 51 \\
\hline $3-3-2$ & -28 & -25 to -30 & 45 & 43 to 50 \\
\hline $5-3-4$ & -12 & -8 to -17 & 45 & 43 to 48 \\
\hline $6-3-1$ & -9 & -5 to -12 & 48 & 45 to 51 \\
\hline $7-3 \cdot 1$ & -7.4 & -4 to -11 & 50 & 47 to 52 \\
\hline $8-3-3$ & -4 & -2 to -8 & 44 & 42 to 47 \\
\hline
\end{tabular}

From the photographs of the cross sections of both the No. 37 and No. 557 burs, the percentage of chip space is indicated in Table II, and was obtained by the use of a planimeter. The values in this table represent the percentage of the total area of the bur blank which has been removed during the process of formation to provide chip clearance space. For the No. 37 burs, it can be seen that the percentage of chip space varies between 31.5 per cent and 40.9 per cent for the seven products examined. In the series of No. 557 burs, the values range from 37 per cent to a maximum value of 54.4 per cent for the ten products studied. This factor of chip clearance space is important in that it provides space between the flutes for the cut particles to accumulate. The larger the chip space, the less the tendency for the clogging of the bur.

TABIEE II

Percentage of Chip Space

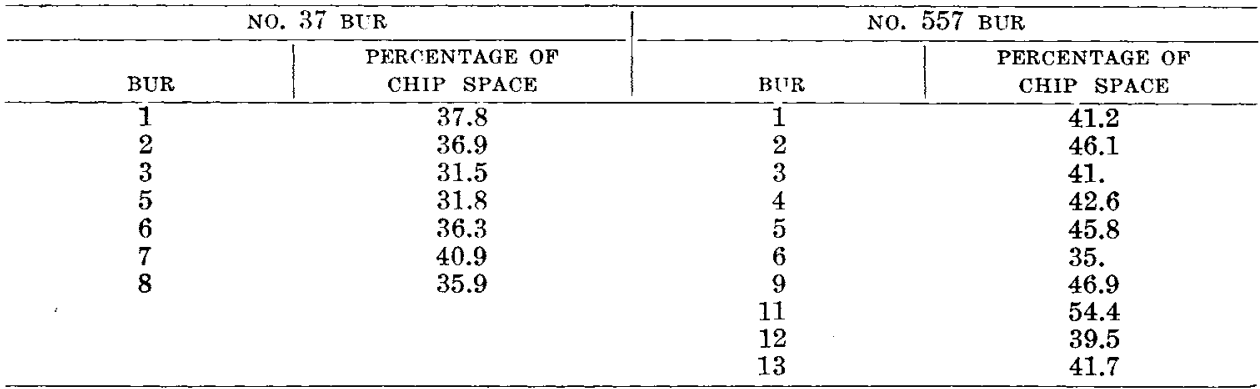

\section{RELATIVE EFFICIENCY}

In order to determine the relative cutting efficiency of the various products, the different burs were used to cut the synthetic plastic material, ivorene, under 
controlled pressures on the bur and with controlled speeds of rotation up to approximately 18,000 r.p.m. Relative comparisons are made in Fig. 8 which indicate the rate of removal in grams per minute when operated with a $500 \mathrm{Gm}$. load (1.1 pound) on a No. 557 type of bur at varying speeds of rotation. It will be observed from this figure that there is considerable variation in the
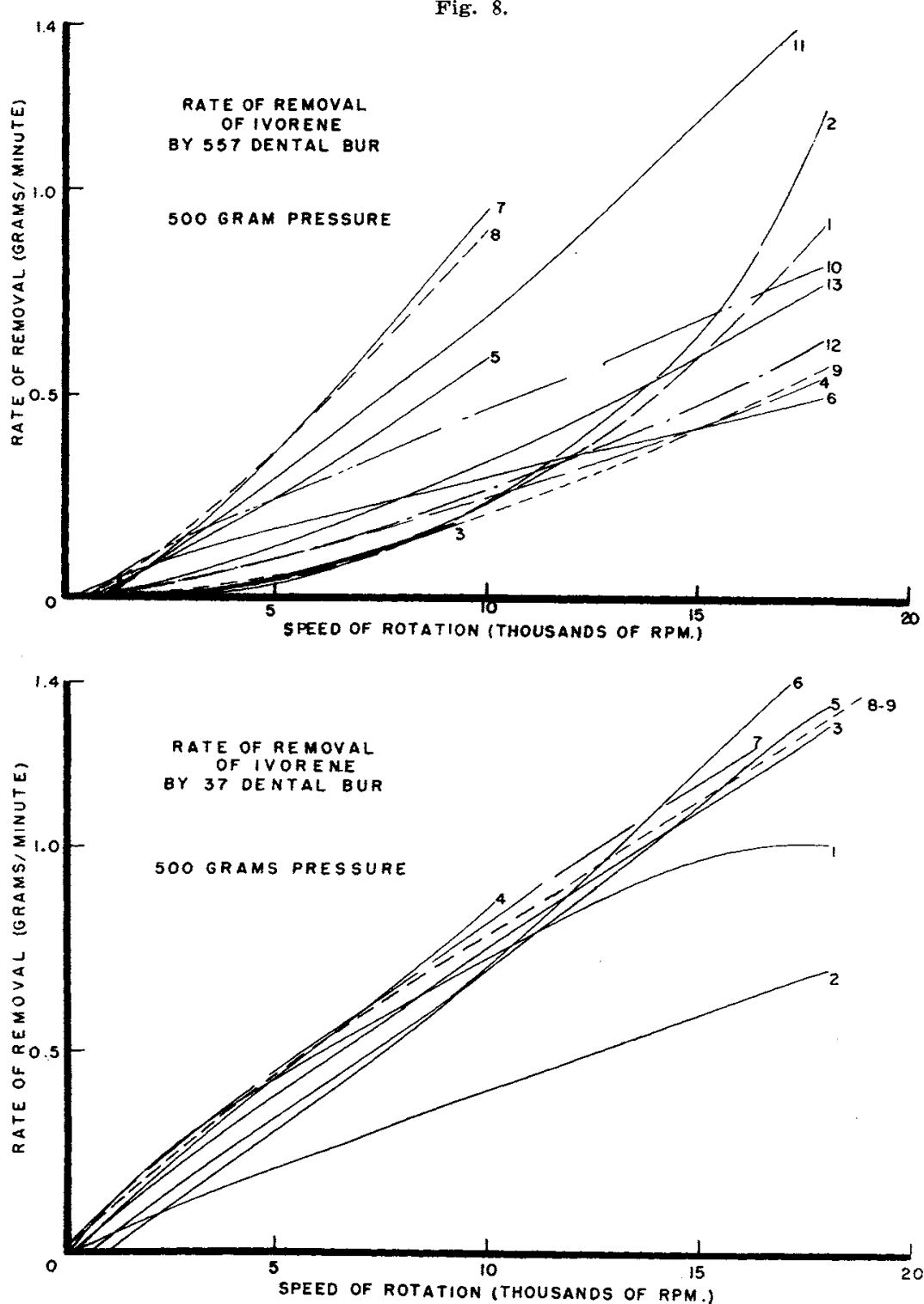

Fig. 9.

Fig. 8.-Relative effectiveness of No. 557 burs.

Fig. 9.-Relative effectiveness of No. 37 burs. 
ability of different burs to cut this material. Ivorene was used for this purpose because it was relatively soft and does not tend to dull the cutting instrument, and also it does not clog the bur badly, so that reproducible values can be obtained. While it would be desirable to compare the cutting efficiency on tooth enamel or dentin, it has not been found practical to determine the weight changes which result from cutting tooth tissue. It is believed that these measurements represent relative or comparative values when cutting a homogeneous material free from the interference of dulling effect on the instrument.

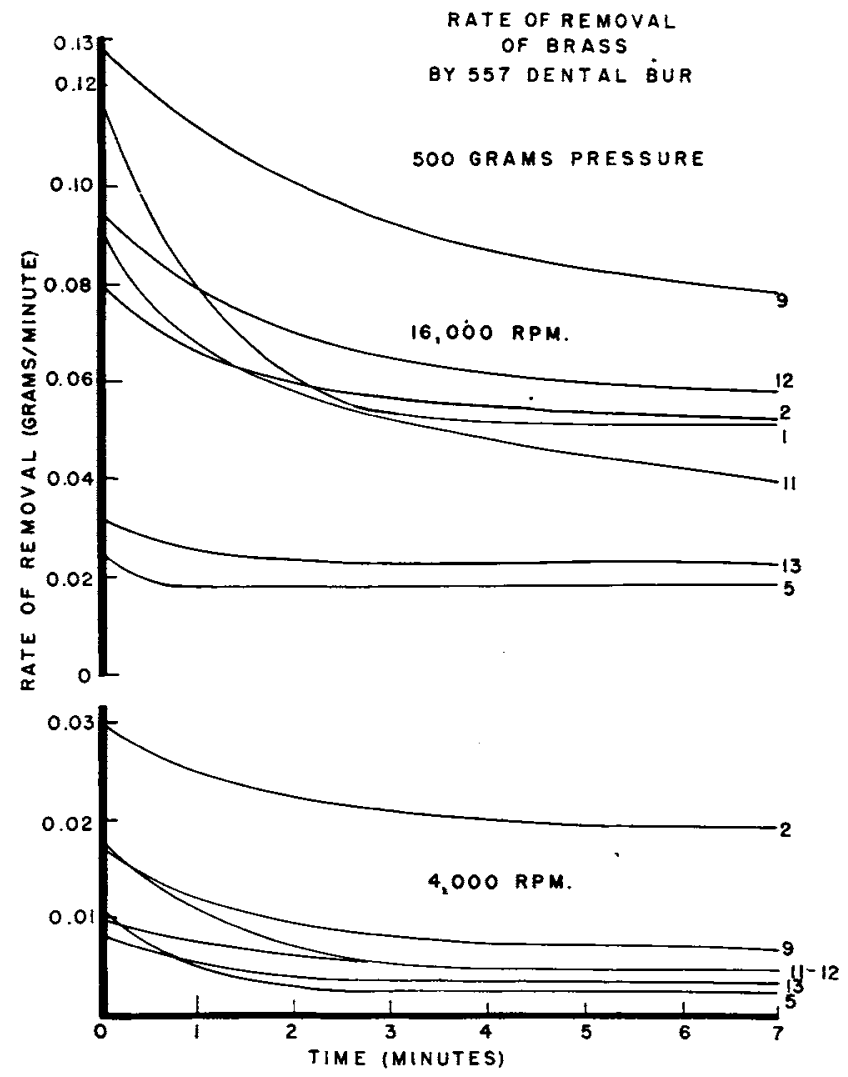

Fig. 10.-Relative life values of No. 557 steel burs.

A full significance of the curves illustrated in Fig. 8 is not yet fully known, and no effort is being made at this time to make detailed comparisons. It has been observed that the uppermost curves in this figure represent six-tooth burs. In general, they seem to be more effective in removing material than are the eight-tooth burs of the same design.

Values for the relative cutting efficiency have also been determined for the No. 37 burs. Values represented in Fig. 9 illustrate the amount of material removed with $500 \mathrm{Gm}$. load at various speeds of operation. With the No. 37 
bur, there is somewhat less scatter among the various products than was observed with the No. 557 bur. In general, also, the slope of the curve is somewhat steeper, which would indicate that the No. 37 type of bur is more effective in removing material at any given speed than is the No. 557 type of bur. Likewise, no effort is made at this time to correlate the results in this figure with those in the previous tables for rake angle and chip clearance space.

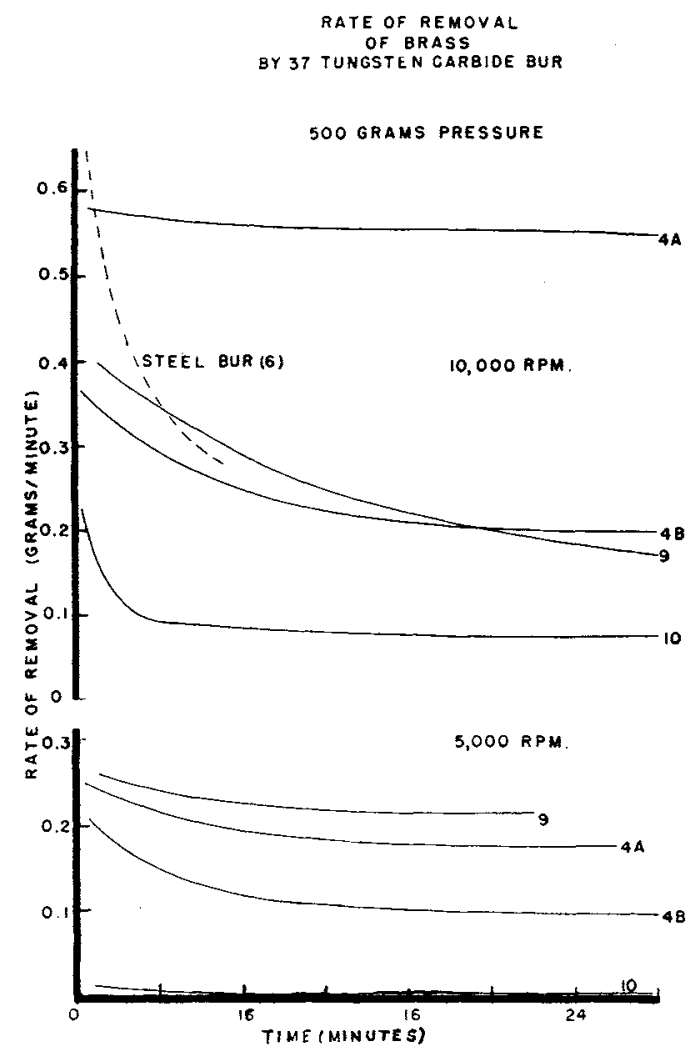

Fig. 11.-Relative life values of No. 37 carbide burs.

\section{COMPARATIVE LIFE VALUES}

In order to determine the functional life of different burs, the relative rate of removal of brass under a given load and speed of operation was measured. In Fig. 10 are shown the relative rates of removal in grams per minute of brass, using steel burs at both 4,000 and 16,000 r.p.m. under a fixed load of $500 \mathrm{Gm}$. (1.1 pounds) on the instrument. A total of seven minutes' cutting time was used with these different burs. From this graph it can be seen that the initial cutting rate was in all instances greater than the cutting rate after one or two minutes. Some burs, like No. 5 and No. 13, were never very effective in removing material, but at the same time did not seem to dull badly during the period of operation. Other burs, like No. 1, had a high initial rate of removal, 
but by the end of three minutes were only approximately one-half as effective as in the beginning.

Some studies have also been made of the relative effectiveness of carbide instruments when cutting brass. The values represented in Fig. 11 show the rate of removal of brass for a No. 37 tungsten carbide bur operated at $500 \mathrm{Gm}$. load and speeds of 5,000 and 10,000 r.p.m. for a total time of approximately twenty-eight or thirty minutes. It is seen that there is also some dulling effect on carbide burs because they do not operate as effectively after five or ten minutes as they did initially. By comparison, however, the steel burs show a much more pronounced drop in effectiveness. This is illustrated by the dotted line on this figure.

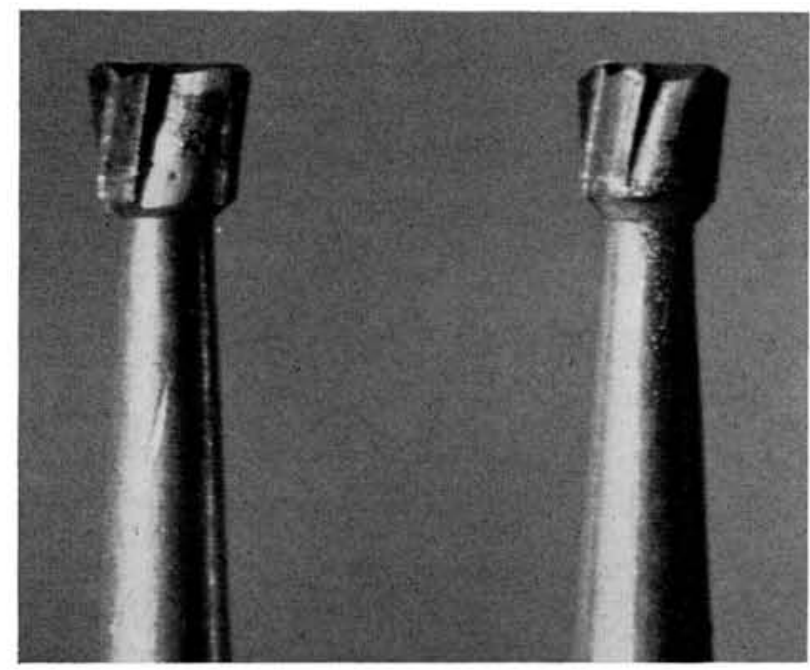

Fig. 12.-A comparison of two carbide burs.

Of some special interest is the value shown for No. $4 \mathrm{~A}$ and $4 \mathrm{~B}$ on Fig. 11. These two burs were of the same brand, but showed considerable difference in their effectiveness in cutting brass. A microscopic examination of these burs revealed that they were not uniform in the degree to which they had been eut during the process of formation. The illustration in Fig. 12 shows that one bur on the left was well formed, while the other on the right was only partially formed. The more completely formed bur is the most effective in removing brass during the cutting operation.

\section{SUMMARY}

Little effort has been made at this time to correlate completely all of the basic design factors of the bur with its relative effectiveness and resistance to dulling. Some correlations appear quite evident, however, and in general, the burs with the more negative rake angle seem to be the least effective in their cutting action. At the same time, they appear to resist dulling to the greatest degree. While it is recognized that numerous other factors enter into the consideration of both 
cutting effectiveness and dulling, it is believed that the basic design of the bur is of great significance and more study is being given to this problem.

\section{REFERENCES}

1. Henry, E. E., and Peyton, F. A.: Vibration Charaeteristics of the Rotating Dental Instrument, $J$. D. Res. 29: 601, 1950.

2. Peyton, F. A., and Vaughn, R. C.: Thermal Changes Developed During the Cutting of Tooth Tissue, Fort. Rev. Chicago D. Soc. 20: 9, 1950.

3. Vaughn, R. C., and Peyton, F. A.: The Influence of Rotational Speed on Temperature Rise During Cavity Preparation, J. D. Res. 30: 737, 1951.

4. Henry, E. E., and Peyton, F. A.: A Study of the Cutting Efficiency of Dental Burs for the Straight Handpiece, J. D. Res. 30: 854, 1951.

5. Peyton, F. A., and Henry, E. E.: Problems of Cavity Preparation With Modern Instruments, New York J. Den. 22: 147, 1952.

6. Peyton, F. A.: Temperature Rise and Cutting Efficiency of Rotating Instruments, New York D. J. 18: 439, 1952. 